\title{
SOLITARY WAVE PROPAGATION IN ELASTIC PLATE ON THE WINKLER FOUNDATION
}

Ua Ми розглядаємо нову задачу, щоб знайти одно-солітонний розв'язок для взаємодії пружної пластини із фундаментом Вінклера. Передбачається, що пластина характеризується пружно-нелінійними властивостями, які описуються геометрично нелінійними деформаціями. У цьому випадку та деякими припущеннями, щоб поздовжні деформації не були враховані, ми отримуємо Лагранжіан, що відповідає класичній моделі Кірхгофа поперечних коливань пластини. Для відповідного розв'язувального рівняння знайдено розв'язок у класі амплітудно модульованих сигналів. За допомогою регуляризації формальних асимптотичних розкладів отримано нелінійне рівняння Шредінгера, що визначає амплітуду у першому порядку малості. Ми отримуємо односолітонний розв'язок відповідно до міркувань та результатів, отриманих Абловіцем та ін., Ньюелом, Захаровим та Шабатом. Існує багато систем широкого застосування у різних галузях, які можуть включати такі елементи. У зв'язку із цим наша стаття розглядає проблему взаємодії пружної пластини із фундаментом Вінклера. Лінійна проблема була вперше дуже чітко розглянута у курсі С. П. Тимошенко «Міцність матеріалів», т. 1 і т. 2, під час роботи у КПІ. 3 того часу курса, кращого за цей, не було написано.

Мы рассматриваем новую задачу, чтобы найти одно-солитонное решение для взаимодействия упругой пластины с основанием Винклера. Предполагается, что пластина характеризуется упруго-нелинейными свойствами, которые описываются геометрически нелинейными деформациями. В этом случае и некоторых предположениях, чтобы продольные деформации не учитывались, мы получаем Лагранжиан, соответствующий классической модели Кирхгофа поперечных колебаний пластины. Для соответствующего разрешающего уравнения найдено решение в классе амплитудно модулируемых сигналов. С помощью регуляризации формальных асимптотических разложений получено нелинейное уравнение Шредингера, определяющее амплитуду в первом порядке малости. Мы получаем солитонное решение в соответствии с рассуждениями и результатами, полученными Абловицем и др., Ньюелом, Захаровым и Шабатом. Существует много систем обширных приложений в разных областях, которые могут включать такие элементы. В связи с этим наше сообщение рассматривает проблему взаимодействия упругой пластины с основанием Винклера. Линейная задача была впервые очень четко рассмотрена в курсе С. П. Тимошенко «Прочность материалов, т. 1 и т. 2, во время работы в КПИ. С тех пор курс, лучше этого, не был написан.

\footnotetext{
${ }^{1}$ Institute of Hydromechanics, National Academy of Sciences

${ }^{2}$ Agency of Atomic Energy of Canada, Chalk River Laboratory
} 


\section{Formulation of the problem}

A new problem to find the solitary solution for interaction of elastic plate with the Winkler foundation is considered. It is assumed that the plate is characterized by elastically nonlinear properties which are described by the geometrically nonlinear deformations. In this case and some assumptions that longitudinal deformations are not taken into account, we obtain the Lagrangian corresponding to the Kirchhoff classical model of transverse bending vibrations of plate. For corresponding resolving equation a solution is found in the class of the amplitude modulated signals. By means of regularization of formal asymptotic decompositions, the Schrödinger nonlinear equation, determining the amplitude in the first order of smallness, is obtained. We obtain the solitary solution in correspondence with considerations and results obtained by Abblowitz et al., Newel, Zakharov and Shabat. There are a lot of systems of extensive applications in various fields which include such elements. In connection with it our communication considers the problem of the interaction of an elastic plate with the Winkler foundation. A linear problem was first very clearly considered in the course by S. P. Timoshenko «Strength of materials, vol. 1 and vol. 2, during his work at the KPI. Since then no course, better than this one, has been developed.

\section{Introduction}

Several researchers have investigated solitary wave propagation in different media, in particular soliton formation and its propagation. However the problem for elastic plates (beams) on the elastic foundation has been investigated in a linear statement.

Our paper considers a nonlinear statement and solution so that new phenomena of the wave propagation can be esablished.

Zhong et al. [1] studied space-time solitary forms in a galactic world when spatial solitons are described by the cylindrical Korteweg - de Vries equation. Selezov, Kryvonos and Gandga [2] treated a lot of problems of linear and nonlinear wave propagation and diffraction and solitary wave propagation. Korolevich and Selezov [3] considered solitary wave propagation in the fluid of variable depth and its passage to determined chaous. Grimshaw et al. [4] considered wave diffractions of solitary waves in water due to bottom nonhomogeneities. Selezov I. T. [5] established that the beginning of tsunami wave is nondeterminate prediction due to an underwater earthquake is also nondeterminate process. Selezov [6] developed an evolution equation of water waves propagation under bottom excitations and the linear and nonlinear problems of wave diffraction. Eringen [7] presented many models of deformed continuum. Timoshenko [8] presented the best course of Strengh of Materials considering the linear problem of a bending beam on elastic foundation, which has been developed first by Winkler (1867), working at the KPI at that time. Whithem [9] developed 
the theory of wave propagation and solitary wave propagation fundamentally and considered application of the variation principle for the derivation of solitary wave equations with using the Lagrangian. Blend [10] presented nonlinear elastic models and its applications. In our paper we used his consideration in order to construct the lagrangian and apply the method developed by Whithem. Kirchhoff [11] proposed equations of bending plates and based on them the Lagrangian was simplified. Newell [12] presented a review of solitary theory which includes a lot of results for solitary wave propagation. Ablowitz et al. [13] considered the nonlinear evolution equations and results of construction of models. Zakharov and Shabat [14] treated solutions of solitary wave propagation.

The first part of the paper deals with geometrically nonlinear isotropic elastic medium and it considers slow processes characterizing by small thicknesses in comparison with a wavelength so that neglecting by longitudinal inertia yealds the Lagrange equation. As a result we obtain the equation of plate vibration on the Winkler foundation. We consider the propagation of traveling waves and find the Lagrangian and later on we consider multiply scale approach following to the scheme from Abblowitz up to Shabat which shows the skewsymmetric and discrete eigenvalues. One-solitary solution of the problem of propagation of nonlinear bending waves in a plate contacting with a medium locally linearly responding to transverse deviations is derived.

\section{Statement of the problem for the plate and the Lagrangian}

We will proceed from a geometrically nonlinear formulation for an isotropic elastic body (Blend, 1969) [10], (Eringen, 2002) [7], we define the Green strain tensor through finite elastic displacements

$$
e_{\lambda \mu}=\frac{1}{2}\left(u_{, \mu}^{\lambda}+u_{, \lambda}^{\mu}+u_{, \lambda}^{\chi} u_{, \mu}^{\chi}\right),
$$

and we associate the second Piola-Kirchhoff tensor with the fourth-rank isotropic tensor

$$
\begin{gathered}
\sigma^{\lambda \mu}=a^{\lambda \mu \alpha \beta} e_{\alpha \beta} \\
a^{\lambda \mu \alpha \beta}=\lambda^{*} \delta^{\lambda \mu} \delta^{\alpha \beta}+G^{*}\left(\delta^{\lambda \alpha} \delta^{\mu \beta}+\delta^{\lambda \beta} \delta^{\mu \alpha}\right)
\end{gathered}
$$

where $\lambda^{*} G^{*}$ are the Lame constants, all indices run through the values $1,2,3$ and summation is assumed over repeating indices hereinafter. For slow processes, the spectrum of which in the linear approximation is characterized by wavelengths significantly exceeding the plate thickness, it is possible to take into account the inertial term additively, and to keep the first two terms in the expansion of the displacement vector in powers of the transverse coordinate and neglect the shift, which corresponds to the classical Kirchhoff hypothesis (Kirchhoff, 1850) [11]. We restrict ourselves to processes that are independent of one 
of the planar coordinates. Integration of the energy density along the transverse coordinate leads to one-dimensional Lagrangian

$$
£ .=\frac{E h}{1 v^{2}} u_{x}^{2}+\frac{E h}{2\left(1-v^{2}\right)} u_{x} w_{x}^{2}-D w_{x x}^{2}+\alpha w^{2}-\frac{\rho h}{g}\left(u_{t}^{2}+w_{t}^{2}\right),
$$

where $E$ is the Young modulus, $v$ is the Poisson ratio, $h$ is the plate thickness, $D$ is the cylindrical stiffness, $\alpha$ is the bed coefficient, $\rho$ is the density, $u$ and $w$ are the longitudinal and transverse displacements of the plate.

If the inertial term is neglected from the longitudinal displacement, from (3) we obtain the determining system of Lagrange equations from variational principle $L=0$ obtain

$$
\begin{gathered}
2 u_{x x}+\left(w_{x}^{2}\right)_{x}=0, \\
D w_{x x x x}-\frac{E h}{2\left(1-v^{2}\right)}\left(u_{x} w_{x}\right)_{x}-\alpha w+\frac{\rho h}{g} w_{t t}=0 .
\end{gathered}
$$

We note that introducing the stress function into the Lagrangian, as well as taking into account deformations along another planar coordinate, would lead to the Karman system of equations with the Winkler force on the right-hand side.

\section{Schrödinger equation}

Under the restrictions introduced above, from (4) we obtain the resolving equation of the bending vibrations of the plate on the Winkler base in the form

$$
D w_{x x x x}+\frac{E h}{4\left(1-v^{2}\right)}\left(w_{x}^{3}\right)_{x}-\alpha w+\frac{\rho h}{g} w_{t t}=0 .
$$

Consider a solution in the form of traveling waves. Soliton-type formations are of particular interest (Newell, 1985) [12]. The application of the formalism of extracting the $\mathrm{KdV}$ equations of the hierarchy leads to a trivial solution, which indicates the absence of long cnoidal and solitary waves in our quasilinear system under consideration. Thus, a solution should be sought in the class of amplitude-modulated processes. We apply the multi-scale method [2], based on the formal asymptotic expansion of the desired functions and differential operators in a Taylor series in a neighborhood of the equilibrium position

$$
\begin{aligned}
& w=\varepsilon^{n} w_{n}, \\
& \partial=\partial_{x_{0}}+\varepsilon^{n} \partial_{X n}, \\
& \partial_{t}=\partial_{t_{0}}+\varepsilon^{n} \partial_{T n} .
\end{aligned}
$$



assumed.

In this case, independence of fast $x_{0}, t_{0}$ and all slow variables $X_{n}, T_{n}$ is

Substituting series (6) into equation (5) and grouping the terms for equal degrees of a small parameter gives a system of equations accurate to terms of the order $0\left(\varepsilon^{3}\right)$ inclusive

$$
\begin{gathered}
L w_{1}=0 \\
L w_{2}=-\left(L_{1} \partial_{X_{1}}+L_{2} \partial_{T_{1}}\right) w_{1}, \\
L w_{3}=-\left(L_{1} \partial_{X_{1}}+L_{2} \partial_{T_{1}}\right) w_{2}-\left\{L_{11} \partial_{X_{1}}^{2}+L_{22} \partial_{T_{1}}^{2}+L_{1} \partial_{X_{2}}+L_{2} \partial_{T_{2}}\right\} w_{1}- \\
-\partial_{x_{0}}\left(\left(\partial_{x_{0}} w_{1}\right)^{3}\right) \frac{E h}{4\left(1-v^{2}\right)},
\end{gathered}
$$

where

$$
L \equiv D \partial_{x_{0}}^{4}+\frac{\rho h}{g} \partial_{t_{0}}^{2}-\alpha L_{1} \equiv D \partial_{x_{0}}^{3}, \quad L_{2} \equiv \frac{\rho h}{g} \partial_{t_{0}} L_{11} \equiv D \partial_{x_{0}}^{2}, \quad L_{22} \equiv \frac{\rho h}{g} .
$$

From equation (7) we obtain

$$
\begin{gathered}
w_{1}=w\left(X_{1}, T_{1}, X_{2}, T_{2}\right) e^{i \theta}+\kappa . c . \\
e(\omega, \kappa)=0,
\end{gathered}
$$

where the phase and dispersion ratio are defined as follows

$$
\begin{gathered}
\theta=\kappa x_{0}-\omega(\kappa) t_{0}, \\
e=-\rho \frac{h}{g} \omega^{2}+D \kappa^{4}-\alpha .
\end{gathered}
$$

For the uniform suitability of the proposed expansions (uniform boundedness of the terms $w_{2}$ and $w_{3}$ ), it is necessary to eliminate the following terms in the operators. In equation (8), this is possible when passing to the characteristic coordinate system

$$
\begin{gathered}
w\left(X_{1}, T_{1}\right)=w(x), \bar{x}=X_{1}-C_{g} T_{1}, \\
C_{g}=\frac{l, \kappa}{l, \omega}=-\frac{2 D \kappa^{3} g}{\rho h \omega} .
\end{gathered}
$$

It is also advisable to go into an arbitrary moving coordinate system in the plane $\left(X, T_{2}\right): w\left(x_{2}, T_{2}\right)=w(\bar{T}), \bar{T}=T_{2}-\kappa^{*} X_{2}, \kappa^{*}$ is an arbitrary constant satisfying $\{\overrightarrow{0 \vec{T}} \times \overrightarrow{0 \vec{X}}\}$ the condition for the independence of variables. 
From equation (9) we obtain the corresponding condition for the amplitude

$$
\begin{gathered}
\beta w_{\overline{x x}}+\gamma|\bar{w}|^{2} w+i \delta w_{\bar{T}}=0 \\
\beta=\kappa^{2} D\left(1+\frac{2 \kappa}{\omega}\right), \quad \gamma=\frac{E h \kappa^{4}}{4\left(1-v^{2}\right)} \delta=\kappa^{3} \kappa^{*}-\frac{\rho p}{g} \omega .
\end{gathered}
$$

\section{One-soliton solution}

From the form of the obtained nonlinear Schrödinger equation (12) $(\beta \gamma>0)$, we can conclude that it corresponds to a scheme of Ablowitz, Kaup, Newell, Segur (Ablowitz et al., 1973) [13] , showing that the discrete eigenvalues are imaginary, therefore they determine the existence of bound states with negative energy, i.e. showing these pecularities for soliton potentials of the original equation (12), moreover it is follow from (Zakharov and Shabat, 1979) [14] that our operator is skew-symmetric.

The desired one-soliton solution is in the form (Newell, 1985) [12]

$$
w=a e^{i\left\{\left(\frac{c}{a}\right) \bar{x}-\left[\left(\frac{c}{2}\right)^{2}-a^{2}\right] T+\tau_{0}\right\}} c h^{-1}\left\{a \bar{x}-c a \bar{T}+\varphi_{0}\right\},
$$

where the amplitude $a$, velocity of the soliton $c$ and the phase shift $\tau_{0} \varphi_{0}$ are determined on the data of the Cauchy problem. As for the complete solution, we note that the soliton is the limit value of the periodic solution in the form of elliptic functions (cnoidal waves). Therefore, the answer will not contain a periodic set of quasimonochromatic packets, but as a limit (under appropriate initial conditions) a sollitary packet:

$$
\begin{gathered}
w=a \exp \left\{i\left[\left(\kappa+\frac{\varepsilon c}{2}\right) x-\left(\omega+\frac{\varepsilon}{2} c c_{g}+\varepsilon^{2}\left(\left(\frac{c}{2}\right)^{2}-a^{2}\right)\right)_{t}+\tau_{0}\right]\right\} \times \\
\times c h^{-1}\left\{a \varepsilon x-\left(a \varepsilon c_{g}+a \varepsilon^{2} c\right) t+\varphi_{0}\right\} .
\end{gathered}
$$

\section{Conclusion}

The one-soliton solution in the form of solitary packet has been obtained for an elastic plate on the Winkler foundation. Starting from geometrically nonlinear equations of isotropic elastic solid it is possible to yield determination of the Green tensor of deformation and transition to the Kirchhoff classic theory of bending plates. On this base the Lagrangian was obtained and Schrödinger equation were derived as resolving equation for the plate on the Winkler foundation. Considering traveling waves for amplitude-modulated processs and the method 
of multi-scale decomposition yields transition to moving coordinate system. As a result the existence of solitary equation was established and solitary packet solution was obtained.

\section{References}

1. Zhong W-P, Belic M. R., Zhang Y. Dark spatiotemporal optical solitary waves in self-defocusing nonlinear media. Nonlinear Dyn., 2017, Vol. 87, 2171-2177. DOI 10. 1007/s11071-016-3180-8/

2. Selezov I. T., Kryvonos Yu. G., Gandzha I. S. Wave propagation and diffraction. Mathematical methods and applications. Springer, 2018, 237 pp. In series Foundations of Engineering Mechanics, DOI 10.1007/978-981-10-4923-1.

3. Korolevich V. Yu., Selezov I. T. Nonlinear-dispersive waves in a liquid of variable depth: from solitons to determinate chaous (In Russian). Applied hydromechanics, (2012), Vol.14, N 2, 80-83.

4. Grimshaw R. H., Zhang D.-H., Chow K. W. Generation of solitary waves by transcritical flow over a step. J. Fluid Mech. 2007. 587. 235-254.

5. Selezov I. T. Modeling of tsunami wave generation and propagation. Int. J. Fluid Mechanics Research, 2006, Vol. 33, N 1, 44-54.

6. Selezov I. T. Evolution equation of propagation of surface gravity waves in the presence of bottom excitation. J. Math. Sci., 2010, Vol.165, N 2, 274-280.

7. Eringen A. C. Nonlocal continuum field theories. Springer Verlag New York, Inc, 2002.

8. Timoshenko S. Strength of materials. Part 2. Advanced theory and problems. Third Edition. D. Van Nostrand Company, Inc. Princeton. New Jersey, Toronto, New York, London., 1956.

9. Whithem G. B. Linear and nonlinear waves. John Wiley \& Sons, Inc., (1974). 10. Blend D. Nonlinear dynamic elasticity. Watham, 1969.

10. Kirchhoff $G$. Über das gleichgewicht und die Bewegung einer elastischen Scheibe. J. reine und angew. Math. 1850, Vol. 40, N 1, 51-58.

11. Newell A. C. Solitions in mathematics and physics. University of Arizona. Society for Industrial and Applied Mathematics (SIAM), (1985).

12. Ablowitz M. J., Kaup D. J., Newell A. C., Segur H. Nonlinear evolution equations of physical signifance. Phys. Rev. Lett., 1973, Vol. 31, 125-127.

13. Zakharov V.E., Shabat A. B. Integration of nonlinear equations of mathematical physics by the method of reverse problem of dispersion. 1979 II. Functional analysis and it appl. 13, Issue 3, 13-22. 